\title{
The Impact of the Exploring Computer Science Instructional Model in Chicago Public Schools
}

\author{
Lucia Dettori \\ DePaul University \\ Ronald I. Greenberg \\ Loyola University Chicago, Rgreen@luc.edu \\ Steven McGee \\ The Learning Partnership \\ Dale Reed \\ University of Illinois at Chicago \\ Follow this and additional works at: https://ecommons.luc.edu/cs_facpubs \\ Part of the Computer Sciences Commons, Curriculum and Instruction Commons, Science and \\ Mathematics Education Commons, Secondary Education Commons, and the Teacher Education and \\ Professional Development Commons
}

Author Manuscript

This is a pre-publication author manuscript of the final, published article.

\section{Recommended Citation}

Lucia Dettori, Ronald I. Greenberg, Steven McGee, and Dale Reed. The impact of the Exploring Computer Science instructional model in Chicago Public Schools. Computing in Science \& Engineering (Special Issue: Best of RESPECT 2015), 18(2):10--17, March/April 2016.

This Article is brought to you for free and open access by the Faculty Publications and Other Works by Department at Loyola eCommons. It has been accepted for inclusion in Computer Science: Faculty Publications and Other Works by an authorized administrator of Loyola eCommons. For more information, please contact ecommons@luc.edu. c) (†) $\odot$

This work is licensed under a Creative Commons Attribution-Noncommercial-No Derivative Works 3.0 License. Copyright (c) 2016 Lucia Dettori, Ronald I. Greenberg, Steven McGee, and Dale Reed 


\title{
The Impact of the Exploring Computer Science Instructional Model in Chicago Public Schools Preprint for Computing in Science \& Engineering, 18(2): 10-17, March/April 2016
}

\author{
Lucia Dettori*, Ronald I. Greenberg ${ }^{\dagger}$, Steven McGee ${ }^{\ddagger}$, and Dale Reed ${ }^{\S}$ \\ ${ }^{*}$ School of Computing, DePaul University, Chicago, Illinois 60604 \\ Email: lucia@cdm.depaul.edu \\ ${ }^{\dagger}$ Dept. of Computer Science, Loyola University, Chicago, Illinois 60611 \\ Email: rig@cs.luc.edu
}

${ }^{\ddagger}$ The Learning Partnership, Western Springs, Illinois 60558, Email: mcgee@lponline.net ${ }^{\S}$ Dept. of Computer Science, University of Illinois at Chicago, Chicago, Illinois 60607 Email: reed@uic.edu

\begin{abstract}
As part of the Taste of Computing project, the Exploring Computer Science (ECS) instructional model has been expanded to many high schools in the Chicago Public Schools system. We report on initial outcomes showing that students value the ECS course experience, resulting in increased awareness of and interest in the field of computer science. We compare these results by race and gender. The data provide a good basis for exploring the impact of meaningful computer science instruction on students from groups underrepresented in computing; of several hundred students surveyed, nearly half were female, and over half were Hispanic or African-American.

Keywords: Computer science education, Computing curriculum
\end{abstract}

\section{INTRODUCTION}

Bureau of Labor Statistics (BLS) 2012-2022 projections show the computer and mathematical occupations group is the fifth fastest-growing of the 22 major occupational groups. Furthermore, salary data released in the first quarter of 2015 show that the other faster-growing categories all have substantially lower average annual pay; for the fastestgrowing category, pay is about one-third that of the computer/mathematical category. BLS also notes that 7 of the 10 largest STEM occupations were related to computers, and 93 of the 100 STEM occupations had average pay significantly above the average of all occupations. In contrast to this bright outlook, women, African-Americans, and Hispanics

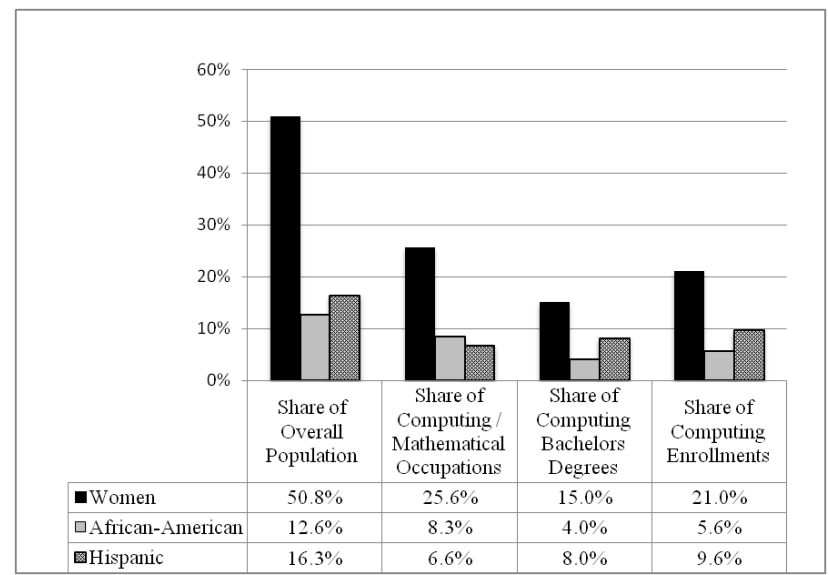

Fig. 1. Data on the three largest demographic groups that are underrepresented in computing. Sources for the first two columns are the 2010 U.S. Census and 2015 BLS statistics. Data for the second two columns come from the Computing Research Association's 2014 Taulbee Survey of selected U.S. and Canadian academic institutions. Despite recent growth in computing enrollments, underrepresented groups are showing only limited improvement.

are vastly underrepresented in the computing-related workforce and educational pipeline as shown in Figure 1.

The disparity in educational outcomes for underrepresented groups at the college level is connected to what happens in high school [1]. Therefore, providing equitable access to high school computer science experiences is a possible avenue for enhancing long-term equity in economic opportunity in 
computer science. This paper investigates the impact of introducing a new computing course experience to high school students in the nation's third largest school district, the Chicago Public Schools (CPS).

\section{THEORETICAL FRAMEWORK}

Differential participation in high school computer science courses is rooted in a variety of individual and social causes. In this paper, we focus on low quality of high school computer science classes as a root cause that is prevalent in lowincome urban school systems. In many of those settings, instruction remains focused on basic computing literacy and use of computer applications. Attempts to take instruction to a higher level often focused on abstract fundamentals of computer programming; many students have difficulty relating to this approach, and computing in high schools and colleges has appealed most strongly to Caucasian boys [2]. In addition, school technology experiences for students in low-income neighborhoods often are very scripted and lack opportunities for engaging in collaborative inquiry [3]. These general results have been replicated by an internal survey of students in computing classes in CPS predating introduction of the instructional model discussed in this work. The students tended to be disappointed with the nature of the computer science content in the classes. In addition, the students felt that the teachers lacked the qualifications to teach computer science since the teachers could not present the concepts in a way that was meaningful to the students.

Outside of school, technology use by youth of all races and genders tends to center around making social connections and working on practical problems. Reorienting computer science instruction around problem-solving experiences that are meaningful to students has the potential to increase the appeal of computer science content [4], [5]. For example, this type of change to introductory courses at Carnegie Mellon was part of a successful program to increase the representation of women in computer science [2].

At the high school level, researchers at UCLA have developed a high school introductory computer science curriculum and professional development program called Exploring Computer Science (ECS). The ECS curriculum seeks to accomplish the goal of broadening participation through activities designed to engage students in computer science inquiry around meaningful problems [6]. Unlike many courses that focus on teaching students how to use computer applications, ECS focuses on helping students develop into problem solvers and creators of technology who can think critically about the role of computing in their lives. At the same time, it avoids the pitfall of characterizing computer science as being primarily about writing programs in a particular programming language. Teacher professional development is a critical component of ECS, preparing teachers to implement the inquiry-based activities while also guiding teachers to build a classroom culture that is inclusive of all students. An important goal of ECS is to broaden participation of women and underrepresented minorities in computer science, and it has had promising results in Los Angeles schools [7], [8]. With continued support from NSF and through a partnership with Code.org, the ECS program has been rapidly expanding to cities across the United States.

The NSF-funded Taste of Computing project in Chicago was one of the first projects to implement and sustain the ECS curriculum and professional development model outside of Los Angeles, starting with the 2011-2012 school year [9]. In this paper, we explore the impact of implementing ECS in a growing number of high schools in CPS. We focused on the construct of inspiration [10] as the theoretical lens for evaluating student outcomes. Inspiration is comprised of three main constructs: cognition, emotional outlook, and career interest. Increasing career interest and positive emotional outlook towards the field without increases in cognitive development leads to disappointment. On the other hand, the development of cognitive aptitude without career interest leads to other career choices. All three constructs of inspiration need to point in the same direction for students to be inspired to pursue a given career. We have begun to work with researchers from SRI with respect to evaluating computational thinking knowledge, skill, and ability outcomes; meanwhile, we report here on outcomes relating to interest and motivation.

\section{METHOD}

This paper focuses on the implementation of ECS in the 2012-13 school year by seven teachers who administered a student end-of-course survey to 349 
students. Almost half the students were girls (48\%), and more than half were Hispanic (36\%) or AfricanAmerican (19\%).

\section{A. Professional Development}

The teachers whose students we surveyed were among the participants in a multi-year ECS professional development (PD) program conducted by university and high school teachers. While this paper focuses on student outcomes, the critical role of professional development in the ECS model makes it important to understand the PD context. In Summer 2012, Taste of Computing hosted two one-week and one three-day PD workshops that involved approximately 75 people including teachers, CPS administrators, and observers from other sites implementing the ECS curriculum. Following the ECS professional development model, Taste of Computing hosted four one-day workshops, spread throughout the 2012-13 academic year, geared towards the same group of teachers that attended the Summer 2012 PDs.

On the first day of the summer workshop, participants completed a background survey based on questions from the Computer Science Teachers Association annual high school survey. The teacher participants in the Taste of Computing workshops represent a relatively experienced group of urban educators with an average of 10 years of teaching experience and almost 7 years of experience specifically teaching computer science. Most of the teachers have primary certifications in business $(58 \%)$ or computer science $(53 \%)$ as well as experience working in the field of computer science (10.8 years average). As a group, they have been active participants in computer science professional development over the previous three years and feel that workshops are the most effective means of professional development. Less than half reported having used Exploring Computer Science prior to Taste of Computing, but most anticipated using the curriculum during the 2012-13 school year.

At the end of each workshop, participants completed a feedback form, which asked for teacher attitudes towards the experience, feedback about what was helpful, and confidence in implementing what was learned.

Of the 61 teachers completing the workshop feedback in Summer 2012, 90-98\% of them responded "most of the time" or "always" (the top two of five choices on a Likert scale) to the questions of how often they felt: "involved in effective professional development", "eager to learn more about the topic", "excited about what you were doing", that the "learning will help you to be a better teacher", that "needs as an adult learner were adequately met", that the "learning can be used in your classroom", and that "the instructor could relate to teachers like you". In addition, $82-89 \%$ of these participants indicated they never or seldom (bottom two of five Likert categories) felt "bored", that "what you were doing was too difficult", or "frustrated or anxious". Teachers also chose only the top three of four categories regarding confidence that they would be able to integrate their workshop learning into the classroom: "Very confident" 55\%, "Confident" $28 \%$, and "Somewhat confident" $17 \%$. For overall satisfaction, all but one teacher made a selection in the top two of five choices, "Very satisfied" or "Satisfied", with the one other teacher giving a neutral response. In addition, each of the schoolyear workshops resulted in over $90 \%$ of the teachers reporting satisfaction.

Through pre-workshop and post-workshop questions, the teachers also showed significant improvement in feeling fairly to very well prepared on each of ten measures directed towards broadening participation in computing. In particular, the percentage of teachers feeling fairly to very well prepared to teach females, racial and ethnic minorities, and students from low socioeconomic backgrounds, increased from $61 \%$ to $69 \%$, from $50 \%$ to $64 \%$, and from $55 \%$ to $73 \%$, respectively. All of these represent medium effect sizes (0.49), which is significant for a weeklong workshop.

The workshop feedback also included extensive open response content indicating teachers found most activities helpful, had few critiques, and often found the experience broadly transformational. For example:

- "I've been gradually coming around to the belief that we should be teaching a computing course to all students. However, since I don't have a background in CS, I didn't know what it should contain. Now, suddenly I've acquired a whole curriculum."

- "I came in as a computer novice but I'm leaving fairly confident I can teach this to students."

Subsequent conversations with several teachers after they had a chance to teach the class for a 
year indicated that the ECS approach to teaching computer science had influenced the way they taught other computer science classes. This was both in response to students expectations and personal belief in the pedagogical approach. This is summarized by the common expression that developed among the community of teachers when referring to changes in their approach to other classes: "Just ECS it."

\section{B. Course Implementation}

There were 42 teachers in 27 schools who taught Taste of Computing courses to over 2600 students. Thirty teachers completed a course implementation survey, which asked teachers to report which lessons they implemented, their perceived level of success at implementing the units, their levels of confidence, and the extent to which they felt the workshops prepared them to implement the curriculum.

Of the 30 teachers who reported on their implementation, over three-fourths of the teachers reported completing the first four units of the Exploring Computer Science curriculum; these four units, Human Computer Interaction, Problem Solving, Web Design, and Programming, are considered to be the critical core portion for courses seeking to follow the ECS approach. In addition, 19\% implemented unit 5 (Computing and Data Analysis) and $42 \%$ implemented unit 6 (Robotics). Most of the teachers $(75 \%)$ felt that the workshops adequately prepared them to implement the curriculum. The extent to which teachers felt that the professional development was effective predicted the number of units that the teachers completed $\left(R^{2}=19 \%\right)$, but did not predict the extent to which teachers felt successful at implementing the units. As indicated above, this study focuses on responses of students in ECS classes taught by the seven teachers who administered surveys to their classes.

The limited number of teachers who surveyed students was due to the complexity of obtaining IRB approval and student/parent consents. We examined the results of the implementation surveys to analyze the extent to which the implementation by teachers who administered the survey was representative of all the teachers who administered the survey. The teachers who administered the survey had slightly higher feelings of success, confidence, and perceptions of professional development effectiveness. In addition, the teachers who administered the survey completed slightly more units. While none of these differences were statistically significant, the overall trend suggests that the students who completed the surveys experienced a slightly higher quality implementation. However, the differences in implementation do not seem to be significant enough to diminish our ability to generalize these findings to the population of teachers who implemented ECS.

\section{Student Survey Instrument}

Students completed an end-of-course survey adapted from items we used in a previous study [11] and surveys used in Los Angeles for ECS evaluation. The student surveys [12] asked for background information (gender, year in school, race, and math grades), level of interest in taking another computer science course and pursuing a major in various subjects in college, and responses to several other questions on a five-level Likert scale. These Likert items were were combined into three measures with high Cronbach reliability, $\alpha$. That is, $\alpha$ is a measure of the internal consistency involved in combining the Likert items into the three generated measures. The Likert items asked for a response ranging from "strongly disagree" to "strongly agree" and were combined into the three measures as follows:

\section{- Awareness of the computing field and its diver-} sity ( $\alpha=0.84)$ : (1) I gained a greater recognition of the diversity of people working in computingrelated fields. (2) I learned more about the kinds of computing-related work people do. (3) I learned more about availability of computing-related career opportunities.

- Perceived value of the ECS course ( $\alpha=0.74)$ : (1) This computer science class is helping me towards my goals. (2) This computer science class gives me skills that help me in other classes. (3) Taking computer science classes is a waste of time. (Reversed) (4) Computer science is enjoyable and stimulating to me.

\section{- Perceived utility of computer science as a field} ( $\alpha=0.72$ ): (1) Knowing more about Computer Science will make me better at problem-solving and critical thinking. (2) The challenge of computer science does NOT appeal to me. (Reversed) (3) I will need computer science skills for my future work/career. (4) I will use computer science in many ways throughout my life. 


\section{Results}

Overall, students rated the value of the class quite high (3.9 out of 5). There were no gender or racial/ethnic differences in students' perceived value of the class. The students' open-ended comments about the class seem to reinforce the high rating. Overwhelmingly, the students felt that the teacher made the class enjoyable. Equity is one of the three key strands interwoven into ECS pedagogy. The fact that the vast majority of students felt a connection with their teacher suggests that the teachers were inclusive of the majority of the students in the class. In addition to equity, the vast majority of students indicated that they enjoyed the challenge, interactivity, and creativity of the class activities, all of which are hallmarks of an inquiry-based classroom setting, which is the second key strand of ECS. (The third strand is computer science content, in which the evaluation of student achievement is at a more incipient stage, through a project being led by SRI, but for which open-ended comments were encouraging.)

Students also gave very strong responses regarding their interest in pursuing further studies in computer science. $74 \%$ of students surveyed indicated increased interest in taking another computer science course as well as in majoring in computer science in college (split about evenly between "increased a little" and "increased a lot"). When asked about interest in majoring in science, engineering, and mathematics, there was still somewhat of an increase of interest, but the neutral responses were two to three times as common as for computer science. This both strengthens the apparent significance of the computer science results and suggests that the curriculum has some success in demonstrating the interconnectedness between computer science and other fields. We also note that the increased interest in computer science was much stronger than in a prior study centering on one-time classroom presentations [11].

\section{A. Open-Ended Comments}

Student open-ended comments also showed positives that were much more abundant and expressive than the negatives. 322 students answered a question on what changes they would suggest, but close to 100 of those responses were essentially "nothing". Among the other responses, it was hard to identify any widespread sentiments except with respect to a non-ECS component included in some of the course offerings to make it a more palatable transition for some administrators. Specifically, some students were given instruction in using Microsoft Office tools for their coursework to the extent that they should be able to pass a certification test. While seven students expressed appreciation for inclusion of that component, 18 commented that it would be better to omit that to allow more focus on more interesting topics, and that advice is prevailing in later offerings of the course. Meanwhile, 330 students responded regarding what they most liked about the course, and their comments connected to all three ECS strands: computer science content, inquiry, and equity.

With respect to content, students very much appreciated the broad-based nature of the course, including both programming and other computer science concepts; students also showed tremendous passion for the subject and often created a multiplier effect by sharing that enthusiasm with family members. Some direct quotes follow:

- "I learned a lot about computer science and engineering and it has really encouraged me to major or minor in these fields."

- "I like that I can use the skills that I learned in a wide variety of fields when choosing a career."

- "Honestly some days I would go to school just to go to my intro to computer science class."

- "It was engaging, and I learned a lot about how computers, programs, and much more worked. I found many connections to daily life."

- "I'd really recommend anyone taking this class because it definitely helped me become more creativewhich is extremely important in what I want to do later in life (journalism)."

- "I got home and I was doing work on the computer and my mother was so astonished at what I was doing. I realized that I was doing stuff that I would never think that I could do before taking this class."

- "I was able to create games for my little brothers to play at home."

- "Even though it is a classroom setting I feel as if I could do this outside of class for fun."

About two dozen comments also related closely to the inquiry-based approach and the opportunities for creativity:

- "I also liked how there was no yes or no answer to a lot of stuff so I could always use my creativity." 
- "What I liked most about this computer science class is that it changes the way you think about everything in life and it challenges you to give thought about everything even simple things."

- "The most I liked is how we use different methods to think on different type of problems. There is a variety of strategies to each type of problem and it makes us think a lot in order to get to a solution."

- "I liked the projects that we did because it helped me as a thinker not just in this class but all of my other classes."

- "Also the problems that arise in class provoke a lot of thought and do not have one clear answer to the problem (most of the time)."

The importance of equity was also implied in comments about students becoming able to do things they never expected and in a few other more direct comments, for example:

- "What I liked the most about this computer science class was it's relaxed environment where everyone was encouraged to contribute and share their opinion."

- "I really like most how I get to work with people on assignments not just have my face plastered to the computer screen. Doing that, I can connect with my classmates and probably learn some different strategies to solve problems or coding ideas."

\section{B. Multiple Regression Analyses}

We conducted a series of multiple regression analyses to identify which factors influence students' interest in pursuing further studies in computer science. Core to the analyses is the extent to which students' course experience as measured by the perceived value of the ECS class increased student interest in pursuing further computer science studies. We also tested whether students' interest in further studies of computer science is mediated by their awareness of the field of computer science and their perceived utility of the field of computer science. In each of the regressions, we controlled for the following demographic factors: gender, race, prior math grades, and grade level. After discussing the main analyses, we summarize places where demographic factors were statistically significant. Table I provides a summary of the regression analyses for the key factors that affected student interest, and Figure 2 provides a graphical summary of the most salient points.
The regression results show that the students' course experience, as measured by perceived value of the ECS class, increased their interest in further computer science studies. The total standardized effect of course experience on interest in taking another high school computer science course was 0.51 on a scale of 0 to 1 . Part of that effect was direct, while a portion was mediated through the influence of course experience on increasing student awareness of the field of computer science and its diversity, and on increasing perceived utility of the field of computer science, each of which, in turn, influenced interest. The direct portion of the effect was 0.23 , while the portion mediated through increased awareness of the field was $0.54 \times 0.17=0.09$, and the portion mediated through perceived utility of the field was $0.77 \times .025=0.19$.

The total standardized effect of course experience on interest in majoring in computer science was 0.32. Part of that effect was direct (0.25), while a portion was mediated through the influence of course experience on increasing awareness of the field of computer science and its diversity, which in turn increased interest $(0.54 \times 0.13=0.07)$. Students' perceived utility of the field of computer science did not have a statistically significant effect on interest in majoring in computer science.

In addition, there were a few analyses where demographic variables were statistically significant after accounting for the effects of the main variables. Older students reported lower perceived utility of computer science as a field $(\beta=-0.10)$. Students with higher self-reported math grades reported higher levels of awareness of the computing field and its diversity $(\beta=0.11)$ and perceived higher course value ( $\beta=0.18)$. African-American students were more likely to increase their interest in taking another computer science course than other students $(\beta=0.28)$. For interest in a computer science major, there was an interaction effect. There were no gender differences among students who rated the value of the course as high. However, for students who rated the value of the class as low value, girls were more likely to decrease their interest than boys $(\beta=0.24)$.

\section{SIGNIFICANCE}

It is significant to note that almost half of the students in the ECS courses in Chicago were girls 


\begin{tabular}{|c|c|c|c|c|c|c|c|c|}
\hline \multirow{2}{*}{$\begin{array}{l}\text { Factors } \\
\begin{array}{l}\text { Perceived Value } \\
\text { of ECS Course }\end{array}\end{array}$} & \multicolumn{2}{|c|}{$\begin{array}{l}\text { Interest in } \\
\text { CS Major }\end{array}$} & \multicolumn{2}{|c|}{$\begin{array}{l}\text { Interest in } \\
\text { Taking Another } \\
\text { HS CS Course }\end{array}$} & \multicolumn{2}{|c|}{$\begin{array}{c}\text { Awareness of } \\
\text { CS Field }\end{array}$} & \multicolumn{2}{|c|}{$\begin{array}{c}\text { Perceived Utility } \\
\text { of CS Field }\end{array}$} \\
\hline & $\beta=0.25$ & $\begin{array}{l}t=3.09 \\
p<0.01\end{array}$ & $\beta=0.23$ & $\begin{array}{l}t=2.98 \\
p<0.01\end{array}$ & $\beta=0.54$ & $\begin{array}{c}t=11.5 \\
p<0.001\end{array}$ & $\beta=0.77$ & $\begin{array}{c}t=21.7 \\
p<0.001\end{array}$ \\
\hline $\begin{array}{l}\text { Awareness of } \\
\text { CS Field }\end{array}$ & $\beta=0.13$ & $\begin{array}{l}t=2.17 \\
p<0.01\end{array}$ & $\beta=0.17$ & $\begin{array}{l}t=2.95 \\
p<0.01\end{array}$ & & & & \\
\hline $\begin{array}{l}\text { Perceived Utility } \\
\text { of CS Field }\end{array}$ & $\bullet$ & $\bullet$ & $\beta=0.25$ & $\begin{array}{c}t=3.36 \\
p<0.001\end{array}$ & & & & \\
\hline$R^{2}$ & \multicolumn{2}{|c|}{$24 \%$} & \multicolumn{2}{|c|}{$32 \%$} & & & \multicolumn{2}{|c|}{$61 \%$} \\
\hline
\end{tabular}

Table I. Regression results showing influence of students' perceived course value on interest in future computer science studies, as mediated by awareness of the computer science field and perceived value of the computer science field. Crosspoints show the standardized

beta coefficient $(\beta)$ for a statistically significant influence from a row label to a column label; the level of statistical significance is also indicated. The bottom row shows the coefficient of determination $R^{2}$, which represents the percentage of variation in the column label that is explained by the multiple regression model.

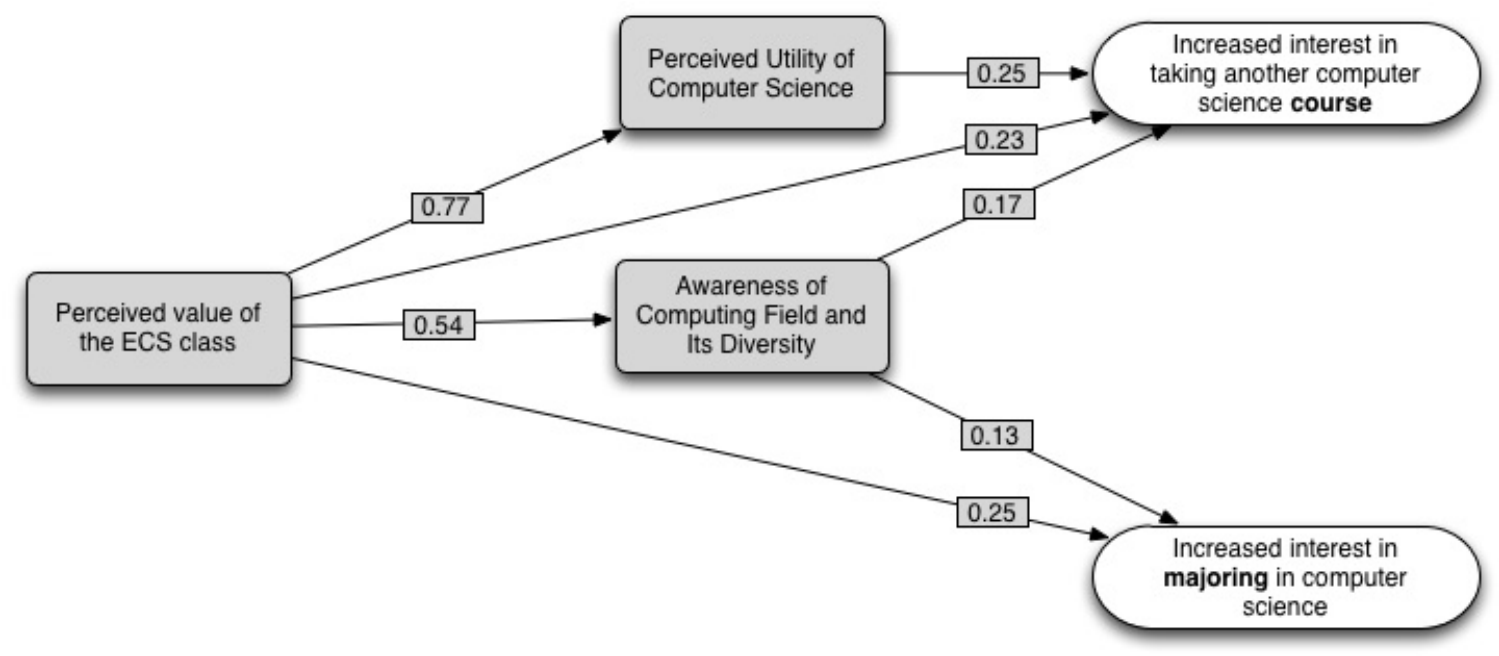

Fig. 2. Path diagram showing the influence of the perceived value of the ECS class on interest in further computer science studies, as mediated by perceived utility of computer science as a field and students' awareness of the computing field and its diversity. The numbers show the standardized beta coeffficient of the regression equation.

(48\%) and more than half of the students were either Hispanic (36\%) or African American (19\%). Roughly three-fourths of the students indicated that the course increased their interest in taking another computer science class and in majoring in computer science in college. The ECS professional development successfully supported teachers in reaching traditionally underrepresented groups in computer science and increasing student interest in pursuing further computer science studies in high school and in college.

There are two policy-related findings. First, for the majority of students who had a positive class experience, there were no gender or racial/ethnic differences in the level of increased interest in taking another computer science class and majoring in computer science, with the exception that African-
American students had a greater increase in interest in taking another computer science class. It would be important for counselors to capitalize on this acrossthe-board increased interest in taking another class by ensuring that this interest translates into registrations for subsequent computer science courses. Second, after controlling for perceived value of the class, the perceived utility of computer science decreased for older students. This finding reinforces the district's Career and Technical Education office recommendation that Exploring Computer Science be taught as a sophomore course. Starting early capitalizes on the higher feelings of utility during sophomore year and creates a trajectory for students to take AP computer science as seniors.

Overall, the students' free response comments about the ECS class suggest that teachers imple- 
mented the class in a way that was meaningful to the students. This meaningfulness translated into overall high perceived value of the class and increased interest in further pursuing computer science classes. If students continue taking computer science classes in high school, it increases their chances of success in college computer science classes, which can open the door to equitable access to computer science careers.

\section{ACKNOWLEDGMENTS}

This work was supported in part by National Science Foundation grants CNS-1138515 and CNS1138417.

\section{REFERENCES}

[1] J. Gal-Ezer and C. Stephenson, "The current state of computer science in U.S. high schools: A report from two national surveys," Journal for Computing Teachers, Spring 2009. [Online]. Available: http://csta.acm.org/Research/sub/Projects/ ResearchFiles/StateofCSEDHighSchool.pdf

[2] J. Margolis and A. Fisher, Unlocking the Clubhouse: Women in Computing. MIT Press, 2002.

[3] J. Margolis, R. Estrella, J. Goode, J. J. Holme, and K. Nao, Stuck in the Shallow End: Education, Race, and Computing. MIT Press, 2008.

[4] R. Christensen, G. Knezek, and T. Overall, "Transition points for the gender gap in computer enjoyment," Journal of Research on Technology in Education, vol. 38, no. 1, pp. 23-37, 2005.

[5] J. King, T. Bond, and S. Blandford, "An investigation of computer anxiety by gender and grade," Computers in Human Behavior, vol. 18, no. 1, pp. 69-84, Jan. 2002. [Online]. Available: http://dx.doi.org/10.1016/s0747-5632(01)00030-9

[6] J. J. Ryoo, J. Margolis, C. H. Lee, C. D. M. Sandoval, and J. Goode, "Democratizing computer science knowledge: Transforming the face of computer science through public high school education," Learning, Media and Technology, vol. 38, no. 2, pp. 161-181, Jun. 2013. [Online]. Available: http://dx.doi.org/10.1080/17439884.2013.756514

[7] J. Margolis, J. J. Ryoo, C. D. M. Sandoval, C. Lee, J. Goode, and G. Chapman, "Beyond access: Broadening participation in high school computer science," ACM Inroads, vol. 3, no. 4, pp. 72-78, Dec. 2012.

[8] J. Goode, J. Margolis, and G. Chapman, "Curriculum is not enough: The educational theory and research foundation of the exploring computer science professional development model," in SIGCSE '14. Association for Computing Machinery, 2014, pp. 493-498.

[9] J. Margolis, G. Chapman, J. Goode, L. Dettori, and D. Lewis, "A tale of three ECS partnerships and why scalability $\neq$ sustainability," ECS Working Paper \#1 http://www.exploringcs.org/wp-content/uploads/2014/04/ A-Tale-of-Three-ECS-Partnerships.pdf, Nov. 2013.

[10] S. McGee, "Looking beyond academic achievement for inspiring the next generation," Paper presented at the annual meeting of the American Educational Research Association, New York., Mar. 2008, available at http://www.lponline.net/papers.html.
[11] S. McGee, R. I. Greenberg, D. F. Reed, and J. Duck, "Evaluation of the IMPACTS computer science presentations," The Journal for Computing Teachers, pp. 26-40, Summer 2013.

[12] R. I. Greenberg and S. McGee, "ECS evaluation survey instruments," http://rig.cs.luc.edu/ rig/ecs/SurveyInstruments. pdf, Oct. 2014, Compilation of multiple surveys: ECS student preSurvey pp. 1-2, ECS student postSurvey pp. 3-4, teacher background suvey pp. 5-11, teacher ECS workshop feedback form pp. 12-13, teacher ECS implementation survey pp. 1424. 